\title{
Doctoral Dissertation Supervision: Identification and Evaluation of Models
}

\author{
Ngozi Agu ${ }^{1}$ and Christy O. Odimegwu ${ }^{2}$ \\ ${ }^{1}$ Department of Educational Foundations, Nnamdi Azikiwe University, Awka +234 , Nigeria \\ ${ }^{2}$ Chris-Harris Research \& Educational Services, Awka +234 , Nigeria \\ Correspondence should be addressed to Christy O. Odimegwu; christiharris2001@yahoo.co.uk
}

Received 29 April 2014; Revised 13 July 2014; Accepted 18 August 2014; Published 8 September 2014

Academic Editor: Eduardo Montero

Copyright (C) 2014 N. Agu and C. O. Odimegwu. This is an open access article distributed under the Creative Commons Attribution License, which permits unrestricted use, distribution, and reproduction in any medium, provided the original work is properly cited.

\begin{abstract}
Doctoral research supervision is one of the major avenues for sustaining students' satisfaction with the programme, preparing students to be independent researchers and effectively initiating students into the academic community. This work reports doctoral students' evaluation of their various supervision models, their satisfaction with these supervision models, and development of research-related skills. The study used a descriptive research design and was guided by three research questions and two hypotheses. A sample of $310 \mathrm{Ph} . \mathrm{D}$. candidates drawn from a federal university in Eastern part of Nigeria was used for this study. The data generated through the questionnaire was analyzed using descriptive statistics and $t$-tests. Results show that face-to-face interactive model was not only the most frequently used, but also the most widely adopted in doctoral thesis supervision while ICT-based models were rarely used. Students supervised under face-to-face interactive model reported being more satisfied with dissertation supervision than those operating under face-to-face noninteractive model. However, students supervised under these two models did not differ significantly in their perceived development in research-related skills.
\end{abstract}

\section{Introduction}

There has been an increase in the demand for doctoral education in Nigeria. This demand is exacerbated by the National Universities Commission and universities' stipulation that Ph.D. is the minimum qualification for teaching in Universities and the ultimatum to those already in the system to acquire the Ph.D. Further, the high rate of unemployment has contributed largely to this rise. Nevertheless, this increase should be a good development for rapidly increasing the quality of education outcome for effective manpower for the nation's development. However, reports of low completion rate as well as poor quality of doctoral dissertation indicate that these ideals might be far from being attained.

According to Scott et al. [1, page 149], doctoral programme is "gold standard" for research study, representing excellence and attracting both resources and prestige". As such, it is expected that its recipients exhibit high levels of proficiency both in research and in disciplinary studies. These highlight the place of doctoral research/dissertation as high point of the doctoral programme. Indeed, Bako [2] established a link between the poor quality of research in the Nigerian universities and the poor doctoral dissertation. Aligning with this position, Henson et al. [3, page 229] argue that "the nature and quality of research is inseparable from the nature and quality of the graduate education and of future education researchers." While they made specific reference to educational research, their argument is obviously validly extended to other disciplines.

Issues surrounding the quality of doctoral research and advisement/supervision have therefore attracted the attention of many scholars [3-9]. Specifically, students' levels of satisfaction with their supervisory experiences vary and the quality of supervision offered has also been questioned ([10, $11]$ cited in $[12,13])$. The discourse on doctoral supervision has also highlighted that doctoral supervisors play a critical role in doctoral education, and doctoral supervision is crucial to successful research education programmes ([14] cited in [15-17]). Further specifying the roles which dissertation supervisors must play to achieve this success in doctoral programme, Mainhard et al. [18, page 360] noted that they "must provide the time, expertise, and support to foster the 
candidate's research skills and attitudes and to ensure the production of a thesis of acceptable standard."

In Nigeria, concerns have been expressed at various quarters on the poor quality of doctoral dissertation. Poor quality of dissertation points to the deficiency in students' research skills. This deficiency has often been traced to the quality of research training the students receive. Indeed, poor dissertation supervision as a form of research training shares the major blame for poor quality of dissertation produced by doctoral students. Hence, a call was made by the National Universities Commission (NUC) to Vice Chancellors to turn more attention to dissertation supervision [2].

Beyond being a local concern, doctoral supervision has been a global issue. For instance, in the USA, the "Carnegie Initiative on the Doctorate" (2001-5), led by the Carnegie Foundation for the Advancement of Teaching, identified supervisors as pivotal to any effort to improve doctoral education [19]. Furthermore, as part of Europe's Bologna Process, the "crucial role of supervision" was recognized in a ministerial agreement on the "Ten Salzburg Principles on the Doctorate," and, at the inaugural meeting of the European University Association Council for Doctoral Education, one of the five themes for doctoral training in Europe was identified as "improving the supervision of $\mathrm{PhD}$ candidates, particularly through better training and monitoring of supervisors" [15, page 80]. However, while developed countries have gone far in initiating policies and programmes in this area, evidence convinces one of the contrary at the local arena. In Nigeria, the quality of postgraduate programme as a policy issue only gained the attention of the NUC recently with the launching of the first Standards for Postgraduate Programme for Nigerian Universities, on December 5, 2011 [20].

It is obvious that the grave concerns on the quality of postgraduate research $[2,21,22]$ have received neither requisite policy nor scholarly attention considering its relevance for ensuring quality in university research in particular and university education in general. This work intends to expose the various dissertation supervision models prevalent in a federal university in Nigeria and to evaluate these models in terms of doctoral students' satisfaction and development in research-related skills.

\section{Dissertation Supervision Models}

The completion of doctoral dissertation is the high point of the entire doctoral programme. In fact, it is the capstone of doctoral programme. It is not surprising then that research supervision, the vital component of the process through which students reach this capstone event, has attracted volumes of research interest. Although a number of scholars (See e.g.; [23]), have proposed and reported the practice of team and collaborative research supervision models, our understanding of doctoral dissertation supervision presented in this work is drawn from the definition of postgraduate supervision proffered by Lategan [24, page 4] who sees it "as the active engagement of a supervisor in assisting the postgraduate student in identifying a line of inquiry, delineating the scope of a project within that line of inquiry, and providing guidance for successful completion of the project and the dissemination of results." This active engagement involves continuous interaction and dialogue between the student (the supervisee) and the supervisor based on the text of the dissertation.

Recognizing this, Wang and Li [25] posit that, in doctoral research, feedback from supervisor plays an important role in assisting student's development throughout the academic research journey. The student benefits from engaging in intellectual exchanges with the supervisor in order to receive guidance on their research progress and thesis writing. It is through the feedback process that the supervisor helps the student go through the research journey towards becoming an independent researcher and a competent scholarly writer. These conceptions presuppose a one-on-one relationship between two persons-the supervisor and the supervisee. Thus we operate with the framework of the traditional dyadic relationship between a supervisor and his/her supervisee. Therefore other supervision models based on groups of three or more are beyond the scope of this paper.

How the entire process of supervision is enacted is relevant also to students' satisfaction with the programme, completion of the programme, and the quality of work that emerges. In line with this, many scholars proffer a number of supervision models/styles as means of enhancing the quality of research supervision and success of doctoral programme [26].

Supervision models have had long tradition in psychology, guidance and counseling, and education, yet there is no clear definition of what a supervision model is. A number of scholars who have been concerned with research supervision, for instance, Gurr [27] and Manathunga [23], discussed research supervision models but did not also proffer a conceptual clarification. Gurr, on his part, used both model and style interchangeably. Drawing from literature in this field, we see research supervision models as forms in which research supervision takes emerging from attitudes, roles, and nature of interaction pattern exhibited by supervisorsupervisee during the supervision process.

A number of these models have been examined over the years. Building on the work of Blumberg [28] and Anderson [29] who highlighted "active" and "passive supervisory" styles, Gurr [27, page 86] developed a model of research supervision which he called supervisor/student alignment model. He theorized that graduate supervision is a means of developing the students to become competently autonomous scholars through the alignment of the students' needs at each stage of the thesis development to the supervisors' supervisory styles through communication and dialogue between the two. This entails a movement between two proposed styles"hand-on" or "hands-off" - as may be determined by the needs of the student at the different stages of his or her work. The relevance of this model lies in promoting discussions and dialogue between the supervisor and the supervisee.

Dysthe [30], from her analysis of the responses of students and professors (supervisors), interviewed on research supervision experiences and developed three models of research supervision-teaching, partnership, and apprenticeship models. The teaching model is based on the traditional 
teacher-student relationship. It builds on asymmetrical power relations where the supervisor gives corrections to the student and controls and directs the student's work. The apprenticeship model involves the supervisee observing and copying the supervisor's actions. Here, the student learns research by engaging in the actual practice of research under the supervisor. In the apprenticeship model of supervision, the student may adopt a position of passivity and the supervisor directs the relationship. In this model, feedback is accepted in an uncritical way, with the students importing suggestions into the text and placing more confidence in the words of the "master" than in their own ability to formulate acceptable texts ([31], cited in [32]).

The partnership model is based on more symmetrical relationship built on dialogue as the central strategy. As observed by Dysthe [30, page 522] "most students equate dialogue with good supervision" and seem to be more comfortable with this model of supervision. The partnership model proposed by Dysthe is akin to the peer-to-peer model described by Wang and $\mathrm{Li}$ [25] where the supervisor regards the student as a practicing academic and as a colleague. The feedback is thus provided in the mentoring model depicted by the supervisor and student engaging in open dialogic exchange of insights and ideas.

The models developed by Dysthe and other scholars seem to be built around face-to-face forms of interaction around texts. Although the face-to-face mode of relationship seems to give both the supervisor and the supervisee the affordances of clarifying understandings and expectations and negotiating meanings $[31,33]$, research evidence shows that the traditional face-to-face models can be supplemented with new technologies. The affordances of these new information and communication technologies (ICT) and realities of heavy workload of supervisors have opened yet another window to what is viewed as the ICT-related dissertation supervision model. One of such mixed models reported by de Beer and Mason [34] is the blended learning model. In blended learning $(\mathrm{BL})$ research supervision, the role of the supervisor is that of indicating the main sources of information to be accessed by the student in face-to-face consultations and via the Internet and libraries and then evaluating what the student has gained from it. This model is believed to have improved the supervision process, reduced administrative workload of the supervisor, and created a dynamic record of the supervision process. Students' evaluation of the innovation shows that it has some limitations which included inability to read body language cues and facial expressions as in face-to-face and being also seen to present communication in an abrupt manner. Consequently, emphasis on face-toface contact early in the supervision process is necessary in order to build rapport, trust, and understanding between the supervisor and student. However, one of the limitations of this approach which may not be an issue in the context of the above research but could be in the Nigerian context is accessibility to ICT facilities. Statistics provided by the National Bureau of Statistics shows that very few have access to various ICT facilities in Nigeria [35]. However, from 2004 to 2008 , this case university had a mandatory programme for the provision of ICT facilities, such as ICT Centres (the
AfriHUB), which provides ICT training and internet services to both students and lecturers. This was followed by the provision of laptops and free internet access to all lecturers. It is expected that both lecturers and students have grown in the culture of using these ICT facilities for various forms of educational activities.

A number of things stand out in the analysis of the various dissertation supervision models reviewed. These are the degree of interaction and dialogue between the supervisor and the supervisee on the one hand and the mode of this interaction (face-to-face or technology mediated) on the other. Furthermore, none of these models have been quantitatively evaluated by the students who are major players in the whole process of dissertation supervision. In line with this, we propose four models of dissertation supervision as follows: the face-to-face interactive model, the face-to-face noninteractive model, the ICT-based interactive model and the ICT-based noninteractive model. In this work, student and supervisee are used interchangeably.

\section{Doctoral Students Satisfaction with and Evaluation of Dissertation Supervision}

It is an age-old practice to elicit information from consumers on their satisfaction with services received. Increasingly, institutions of higher education in the developed countries have recognized their students as primary consumers. Hence the institutions consider the satisfaction of the students' needs vital to their existence. Student satisfaction refers to the favourableness of a student's subjective evaluation of the various outcomes and experiences associated with education $[36,37]$. Student satisfaction with dissertation supervision is therefore seen as a student's subjective favourable evaluation of the interaction and encounter with the supervisor during the dissertation writing process.

It is believed that the assessment of students' satisfaction with educational services has positive outcome for both students and the institution. It increases the chances of students' completion of their programme, their self-motivation, and their success in the programme. On the other hand, the institution would be more prepared to deliver services that would meet students' needs and improve the services and the chances of the students coming back for further studies as well as the students' positive recommendation of the institution to others [37].

Following this line of reasoning, such practice as student evaluation of teaching (SET) was introduced in most developed countries. The volume of research drawing attention to its relevance $[38,39]$ and those questioning the reliability and relevance of the practice [40-43] show how controversial it has become. However, evaluation of dissertation supervision which is a major aspect of research training has not received much empirical investigation. This lack observed by Marsh et al. [44] was reechoed by Mainhard et al. [18, page 360] who noted that "in many institutions it is not common to evaluate supervisory experience...."

However, a very significant contribution to the evaluation of research supervision model is the work of Gurr [27, page 
88] in Sidney. He did a trial testing of the "student/supervisor alignment model" as a supervisory tool with four of his doctoral students. He noted that the model enhanced student's research ability which he described as "competent autonomy" such that one of the participant's papers won that year's best student paper and subsequently the participant produced "three refereed papers." Apart from these observable indicators of the effectiveness of this model, he further sought feedback from the students on the relevance of the model, to which most of the students commented that they found the model useful. Although Gurr's study was a trial of a model's effectiveness using case study approach, the use of very few students from a single department and emphasis on a single model are some of its limitations.

This work therefore extends this field of research by examining dissertation supervision models in use, doctoral students' satisfaction with supervision experience, and contribution of these models to development of research-related skills using a larger sample of doctoral students from diverse disciplines. The following research questions guided this study.

\section{Research Questions}

(1) What are the dominant research supervision models used in doctoral dissertation supervision?

(2) How do doctoral students involved in the different supervision models compare in terms of satisfaction with dissertation supervision?

(3) How do doctoral students involved in the different supervision models compare in their evaluation of the contribution of dissertation supervision to development of research-related skills?

Hypotheses

(1) Doctoral students under different models of dissertation supervision will differ significantly in their selfreport of satisfaction with dissertation supervision.

(2) Doctoral students under different models of dissertation models will differ significantly in their self-report of acquisition of research-related skills.

Context of the Study. The empirical site is a federal university in South-Eastern part of Nigeria. It enrolls quite a high number of doctoral students. The student population is predominantly Igbo. However, the official language in Nigeria is English Language. Between 2004/2005 and 2010/2011, the university enrolled about 1339 doctoral students. Doctoral candidates must have 3.5 (at 5 point scale) in the degree of master to qualify for admission. On admission, students are assigned dissertation supervisors. The minimum duration for the programme is 24 months for full-time and 36 months for part-time students while the maximum duration is 60 months and 72 months for full-time and part-time students respectively. Students are expected to take a minimum of 9 and maximum of 12 unit courses. The dissertation writing is a very significant part of the programme. Students choose dissertation topics after the course work. They are expected to go through three stages of dissertation oral presentation (department, faculty, and external) before the degree is awarded. The first stage, called the proposal defence which comes up when the student completes three chapters (introduction, literature review, and methods), the faculty defence when the five chapters are completed, and then the external which marks the end of the programme and the award of the degree. The university lecturers have a very high workload as some lecturers supervise as much as 20 doctoral students as against the minimum of five stipulated in the postgraduate regulations. This is coupled with the demands of master's and undergraduate programmes. There is also a high level of low completion rate: less than $10 \%$ of the doctoral students graduate within due date.

\section{Methods}

The study is a descriptive survey. The sample was 310 doctoral students drawn through simple random sampling from the list of 1,260 doctoral students registered between 2005/2006 and 2009/2010 academic sessions. Of the 310, 228 returned their questionnaire which represents $74 \%$ return rate. This number consisted of 104 males (45.6\%) and 124 females (54.4\%) who have been in the programme for a minimum of 1 year and a maximum of 5 years. While $84(36.8 \%)$ were on full-time programme, $144(63.2 \%)$ were on parttime. Most of the participants $158(68 \%)$ were at the proposal preparation stage of their dissertation, 64 (28\%) were still at topic selection stage while quite a few, 8 (3.5\%) respondents were waiting for their external/final defence. The distribution of sample according to faculties were as follows; education 71 (31\%); social sciences 46 (20\%); management sciences 52 (23\%), arts $21(9 \%)$, and environmental sciences 39 (17\%).

The instrument used for data collection was a 32-item questionnaire. Six items from the instrument elicited demographic and programme information from the students. Of the 26 questions that addressed the research aims, 15 were descriptors of different models of dissertation supervision to which students responded on a five-point Likert-type scale which consisted of almost always (5), frequently (4), sometimes (3), rarely, (2) and almost never (1). The items were distributed as follows; face-to-face interactive modelsix items; face-to-face noninteractive model-five items; ICTbased interactive model-two items and ICT-based noninteractive model-two items. Students' satisfaction with dissertation supervision and development of research-related skill were measured by two subscales (supervision and skill development) of Postgraduate Research Experience Questionnaire (PREQ) adapted from previous study by Australian Council for Educational Research as reported by Ainley [10]. The satisfaction with supervision had six (6) questions based on a five-point Likert-type scale: very satisfied (5); satisfied (4), neither satisfied or dissatisfied (3); dissatisfied (2); and very dissatisfied (1). The contribution of dissertation supervision to doctoral students' development of research-related skills was measured using five (5) items that made up the skill development subscale of PREQ. The response format was 
TABLE 1: Questionnaire items' mean and standard deviation scores.

\begin{tabular}{|c|c|c|c|c|c|}
\hline & $N$ & Minimum & Maximum & Mean & $\begin{array}{l}\text { Std. } \\
\text { Deviation }\end{array}$ \\
\hline \multicolumn{6}{|l|}{ Face-to-Face interactive model } \\
\hline (1) My submissions are made directly to my supervisor or to his/her office & 20 & 1.00 & 5.00 & 4.14 & 1.13 \\
\hline (2) I have direct and interpersonal interaction with my supervisor on my submissions & 20 & 1.00 & 5.00 & 4.30 & .88 \\
\hline (3) My supervisor and I have interpersonal discussions on feedback on my work & 20 & 1.00 & 5.00 & 4.04 & .84 \\
\hline (4) My supervisor gives me direct feedback on my work/write up & 20 & 1.00 & 5.00 & 4.11 & .85 \\
\hline $\begin{array}{l}\text { (5) My supervisor gives me the opportunity to make my own contributions and } \\
\text { justifications for my positions }\end{array}$ & 20 & 1.00 & 5.00 & 3.91 & .96 \\
\hline (6) Feedback from my supervisor includes oral/verbal face to face discussion & 20 & 1.00 & 5.00 & 3.35 & 1.22 \\
\hline \multicolumn{6}{|l|}{ Face-to-Face noninteractive model } \\
\hline (7) I submit my written work directly to my supervisor or to his/her office & 228 & 1.00 & 5.00 & 2.14 & 1.24 \\
\hline (8) Feedbacks are mainly written comments & 228 & 1.00 & 5.00 & 3.91 & 1.09915 \\
\hline (9) I am not given the opportunity to discuss or justify my position & 228 & 1.00 & 5.00 & 2.31 & 1.25 \\
\hline (10) Feedback from my supervisor are mainly directives and instructions & 228 & 1.00 & 5.00 & 3.11 & 1.20 \\
\hline (11) There is not much interpersonal interaction with my supervisor & 228 & 1.00 & 5.00 & 2.53 & 1.38 \\
\hline \multicolumn{6}{|l|}{ ICT-based interactive model } \\
\hline (12) I forward my work to my supervisor through his/her email & 228 & 1.00 & 5.00 & 1.70 & .84 \\
\hline (13) I discuss my work with my supervisor(s) through phone/skype/chat forum & 228 & 1.00 & 2.00 & 1.47 & .50 \\
\hline \multicolumn{6}{|l|}{ ICT-based noninteractive model } \\
\hline (14) I send my written work to my supervisor his/her through email & 20 & 1.00 & 2.00 & 1.56 & .49 \\
\hline (15) Feedbacks are received through the email without further discussions & 20 & 1.00 & 2.00 & 1.51 & .50 \\
\hline Satisfaction with dissertation supervision & 20 & 1.00 & 2.00 & 1.56 & .49 \\
\hline (16) Availability of supervisor when needed & 20 & 1.00 & 5.00 & 2.58 & 1.29 \\
\hline (17) Supervisor's effort to understand difficulties you are faced with & 20 & 1.00 & 5.00 & 2.32 & 1.17 \\
\hline (18) Supervisor's provision of additional information relevant to your topic & 20 & 1.00 & 5.00 & 2.28 & 1.32 \\
\hline (19) Supervisor's guidance on topic selection and refinement & 20 & 1.00 & 5.00 & 2.25 & 1.08 \\
\hline (20) Supervisor's provision of feedback on your work & 20 & 1.00 & 5.00 & 2.18 & .94 \\
\hline (21) Supervisor's guidance on methods/technical issues of your research & 20 & 1.00 & 5.00 & 2.35 & 1.00 \\
\hline \multicolumn{6}{|l|}{ Development of research-related skills } \\
\hline (22) I have learnt to develop my ideas and present them in a written form & 20 & 1.00 & 5.00 & 2.09 & .87 \\
\hline (23) My analytic skills have been sharpened & 20 & 1.00 & 4.00 & 1.98 & .81 \\
\hline (24) I have developed the ability to plan my own work & 20 & 1.00 & 5.00 & 1.97 & .90 \\
\hline (25) My skill in writing research articles have been enhanced & 20 & 1.00 & 4.00 & 1.95 & .91 \\
\hline (26) I have more confidence in tackling possible research problems in my field & 20 & 1.00 & 4.00 & 2.03 & .78 \\
\hline
\end{tabular}

based on a five-point Likert-type scale of strongly agree (5), agree (4), undecided (3), disagree (2), and strongly disagree (1). The questionnaire was pretested using a sample of 20 doctoral students prior to this study. Cronbach's alpha was used to establish the reliability of the questionnaire subscales. The alpha coefficients were $.75, .51, .95, .67, .91$, and .85 for face-to-face interactive model, face-to-face noninteractive model, ICT-based interactive model, ICT-based noninteractive model, satisfaction with dissertation supervision and development of research-related skills subscales, respectively. The questionnaire items, the mean and the standard deviation scores are shown in Table 1.

The data collected were analyzed using mean, standard deviation, and $t$-test. SPSS version 17.0 was used for the data analysis. The summated scale gave overall mean rating for all items in each supervision model. Individual student's mean rating was used to classify them into different models. Each student was classified into the model for which he or she obtained the highest mean rating. Two main models emerged: the "face-to-face interactive model" and "face-to-face noninteraction model". $t$-test was used to compare difference in students' mean rating of satisfaction with supervision and contribution to their development of research-related skills.

\section{Results}

The face-to-face interactive model has minimum mean rating of 2.14 and maximum rating of 4.86 and a mean of 4.00 , while face-to-face noninteractive model has minimum rating of 1.17 and maximum 4.50 and mean of 2.66. Both ICT-based models (interactive and noninteractive) have minimum and maximum values of 1 and 2 while the mean values were 1.52 and 1.53, respectively. The mean values show that the Face-toFace Interactive Model was most frequently used, followed by 
TABLE 2: Descriptive statistics on the various models of supervision.

\begin{tabular}{lccccc}
\hline & $N$ & Min. & Max. & Mean & Std Deviation \\
\hline Face-to-face interactive model & 228 & 2.14 & 4.86 & 4.00 & .66 \\
Face-to-Face noninteractive model & 228 & 1.17 & 4.50 & 2.66 & .72 \\
ICT-based interactive model & 228 & 1.00 & 2.00 & .52 & .46 \\
ICT-based noninteractive model & 228 & 1.00 & 2.00 & & .43 \\
& Total $=228$ & & & \\
\hline
\end{tabular}

TABLE 3: Percentage distribution of students within dissertation supervision models.

\begin{tabular}{lcc} 
& Frequency & Percent \\
\hline Face-to-face interactive model & 199 & 87.3 \\
Face-to-face noninteractive model & 29 & 12.7 \\
\hline Total & 228 & 100.0 \\
\hline
\end{tabular}

the Face-to-Face Non-interactive Model while the two ICT models (Interactive and Non-interactive) were either "rarely" or "never" used (Table 2).

5.1. Dominant Research Supervision Models/Styles Used in the Process of Doctoral Students' Dissertation Supervision. The categorization of students into each of the models for which they had the highest mean rating showed that greater proportion of doctoral students $(87.3 \%)$ in the dissertation supervision process engage often in the "face-to-face interactive model" while very few doctoral students (12.7\%) engage often in the "face-to-face noninteractive model" (Table 3).

\subsection{Relative Satisfaction with Dissertation Supervision among} Students within the Different Dissertation Supervision Models. The overall mean satisfaction for dissertation supervision for the face-to-face interactive model was 3.64 while that of students under face-to-face noninteractive model was 2.11. The mean value for the former was above the scale average of 3.00 while that of students within the noninteractive was below the scale average. Therefore, while students who were supervised with the face-to-face interaction model rated their satisfaction with the whole dissertation supervision experience above average, those supervised using noninteractive model reported being less satisfied. Their standard deviations were also wide apart (1.08 and .59), respectively. The high standard deviation of the face-to-face interactive models shows that there is large variability in satisfaction among students in that group when compared to those in Noninteractive models.

The use of $t$-test to examine the significance of the mean difference showed that difference was significant, $t$ (226) $=11.52, P<0.05$. It was concluded that students who most frequently engaged in face-to-face interactive model of dissertation supervision were likely to be more satisfied than those who mostly engaged in face-to-face noninteractive model of dissertation supervision (Table 4).
5.3. Perceived Contribution of Dissertation Supervision to Doctoral Students' Development of Research-Related Skills in Relation to the Different Dissertation Supervision Models. The overall mean rating of students on the contribution of dissertation to the development of their research-related skills was 3.50 for students who mostly use the face-to-face interactive model and 3.35 for students under the face-to-face noninteractive model. Although there is a mean difference of .15 in favour of the face-to-face interactive model, the two mean values were slightly above the scale average of 3.00. Their standard deviation seems comparable relative to their mean. By these mean ratings, doctoral students believed that their dissertation supervision experience has moderate contribution to the development of their research-related skills.

The $t$-test results confirmed that the mean difference between the two groups was not significant as shown by the $t(226)=.65, P>0.05$. It was concluded that students under face-to-face interactive model of dissertation supervision and those under face-to-face noninteractive model of dissertation do not differ in their views on contribution of dissertation supervision to development of research-related skills (Table 5).

\section{Discussion of Findings}

This study was aimed at determining the dominant doctoral dissertation supervision models in use in a university setting, students' rating of their satisfaction with supervision experience, and the contribution of this experience to the development of their research-related skills. One of the major findings was that face-to-face interactive model was not only the most frequently used model but also the most widely used while the ICT-based models (interactive and noninteractive) were almost never used. This seems to support the position held by Gurr [27] that "passive" model of supervision is not acceptable in a university system. Literature showed that there is a wide consensus among scholars that doctoral 
TABLE 4: $t$-test for difference in doctoral students' satisfaction with dissertation supervision by two models of dissertation supervision.

\begin{tabular}{|c|c|c|c|c|c|c|c|}
\hline & Supervision models & $N$ & Mean & Std. Dev. & $\mathrm{df}$ & $t$ & $P$ value \\
\hline \multirow{2}{*}{$\begin{array}{l}\text { Perceived satisfaction with } \\
\text { dissertation supervision }\end{array}$} & $\begin{array}{l}\text { Face-to-face interactive } \\
\text { model }\end{array}$ & 199 & 3.64 & 1.08 & 226 & 11.52 & .00 \\
\hline & $\begin{array}{c}\text { Face-to-face noninteractive } \\
\text { model }\end{array}$ & 29 & 2.11 & .59 & & & \\
\hline
\end{tabular}

TABLE 5: $t$-test for difference in doctoral students' research skill development by two models of dissertation supervision.

\begin{tabular}{lcccccc}
\hline & Supervision models & $N$ & Mean & Std. Dev. & df & $t$ \\
\hline $\begin{array}{l}\text { Perceived development in } \\
\text { research-related skills }\end{array}$ & $\begin{array}{c}\text { Face-to-face interactive } \\
\text { model }\end{array}$ & 199 & 3.50 & .88 & 226 & .65 \\
\hline $\begin{array}{c}\text { Face-to-face noninteractive } \\
\text { model }\end{array}$ & 29 & 3.35 & .58 & .52 \\
\hline
\end{tabular}

dissertation should be largely defined by interaction and dialogue between the supervisor and the supervisee. The lack of adoption of ICT-based models may be evidence that supervisors are not yet conscious of the opportunities provided by ICT for the improvement of educational provisions and as means of reducing dissertation supervision workload.

This study further revealed that students operating within the face-to-face interactive model express more satisfaction with their dissertation experience than those in the noninteractive model. However, these two models did not differ significantly in their contribution to development of research skills in the student. This could be as a result of the dynamism in dissertation supervisory interaction reported by Gurr [27] which suggests that each model (hands-on or hands-off) is relevant at different stages of the students' work. Three possible conclusions could be that the supervisor's hands-off (noninteraction) at certain stages of the work is an opportunity for the student to work independently and acquire more skills independently or that supervisors "handson" or interaction practice at some point of the dissertation may be an inhibition to the students' development. Further possibility could be viewed in the nature and quality of the feedback given by the supervisors, the nature of the interaction between the supervisor and the supervisee and the supervisee's ability to undertake the dissertation component of the doctoral programme.

\section{Conclusion}

The dissertations produced by doctoral students in some Nigerian universities have been judged to be below standard. There is also low completion rate in the programme in which some scholars attribute to dissertation supervision problem. The lack of commensurate policy and research attention on doctoral programme, especially in doctoral supervision, both at the national and institutional levels might be a factor contributing to these. This work therefore examined the doctoral thesis supervision models in one university, students' satisfaction with these models and possible contribution to the development of research-related skills. It found that although the face-to-face interactive model was the most widely used and that students supervised using this model were more satisfied with dissertation supervision, they did not report greater development in research-related skills than those supervised with face-to-face non-interactive model. This questions the quality of feedback given to students by their supervisors, the quality of interaction between the supervisors and supervisees and perhaps the quality of students enrolled into the programme.

ICT-based models are yet to be adopted in the doctoral dissertation process despite their potential for reducing the high workload lecturers experience in this university. There is therefore the need to create awareness by the institution. The findings open up new vistas for further research and opportunity for changing institutional practices as regards doctoral dissertation supervision and skill development.

The authors acknowledge some of the limitations of this study. Although this study provided a detailed description of the context of this study to facilitate evaluation of applicability of the findings to different contexts, it is still a single institutional study. Only students' perspective was covered in this study, future research study may undertake a comparative analysis of supervisors' and supervisees' perspectives. Furthermore, the study did not take into cognizance the disciplinary differences and practices in research which may affect research supervision practices. These and other factors which may account for students' development of researchrelated skills need to be explored further in research.

\section{Conflict of Interests}

The authors declare that there is no conflict of interests regarding the publication of this paper.

\section{References}

[1] D. Scott, A. Brown, I. Lunt, and L. Thorne, Professional Doctorates: Integrating Professional and Academic Knowledge, Society for Research into Higher Education and Open University Press, Berkshire, UK, 2004.

[2] S. Bako, "Universities, research and development in Nigeria: time for a paradigmatic shift," in Proceedings of the 11th General Assembly of CODESRIA, on Rethinking African Development: Beyond Impasse, Towards Alternatives, pp. 2-316, Maputo, Mozambique, December 2005. 
[3] R. K. Henson, D. M. Hull, and C. S. Williams, "Methodology in our education research culture: toward a stronger collective quantitative proficiency," Educational Researcher, vol. 39, no. 3, pp. 229-240, 2010.

[4] D. Archbald, "Research versus problem solving for the education leadership doctoral thesis: implications for form and function," Educational Administration Quarterly, vol. 44, no. 5, pp. 704-739, 2008.

[5] N. K. Duke and S. W. Beck, "Education should consider alternative formats for the dissertation," Educational Researcher, vol. 28, no. 3, pp. 31-36, 1999.

[6] A. Holbrook, S. Bourke, T. Lovat, and H. Fairbairn, "Consistency and inconsistency in $\mathrm{PhD}$ thesis examination," Australian Journal of Education, vol. 52, no. 1, pp. 36-48, 2008.

[7] T. W. Maxwell and R. Smyth, "Research supervision: the research management matrix," Higher Education, vol. 59, no. 4, pp. 407-422, 2010.

[8] C. Riehl, C. L. Larson, P. M. Short, and U. C. Reitzug, "Reconceptualizing research and scholarship in educational administration: learning to know, knowing to do, doing to learn," Educational Administration Quarterly, vol. 36, no. 3, pp. 391-427, 2000.

[9] L. S. Shulman, C.M. Golde, A.C. Bueschel, and K. J. Garabedian, "Reclaiming education's doctorates: a critique and proposal," Educational Researcher, vol. 35, no. 3, pp. 25-32, 2006.

[10] J. Ainley, The 1999 Postgraduate Research Experience Questionnaire, DETYA, Australian Council for Educational Research, Evaluations and Investigations Programme, Higher Education Division, Canberra, Australia, 2001.

[11] R. Neumann, The Doctoral Education Experience: Diversity and Complexity, Department of Education Training and Science, Canberra, Australia, 2003.

[12] N. Murphy, J. D. Bain, and L. Conrad, "Orientations to research higher degree supervision,” Higher Education, vol. 53, no. 2, pp. 209-234, 2007.

[13] G. Wisker, "Learning conceptions and strategies of postgraduate students: Israeli $\mathrm{PhD}$ students-and some steps towards encouraging and enabling their learning," in Proceedings of the 2nd Postgraduate Experience Conference, Cape Town, South Africa, April 1999.

[14] B. J. Barnes and A. E. Austin, "The role of doctoral advisors: a look at advising from the advisor's perspective," Innovative Higher Education, vol. 33, no. 5, pp. 297-315, 2009.

[15] C. Halse and J. Malfroy, "Retheorizing doctoral supervision as professional work," Studies in Higher Education, vol. 35, no. 1, pp. 79-92, 2010.

[16] G. Harman, "Producing PhD graduates in Australia for the knowledge economy," Higher Education Research \& Development, vol. 21, no. 2, pp. 179-190, 2002.

[17] C. M. Golde, "Should i stay or should i go? Student descriptions of the doctoral attrition process," Review of Higher Education, vol. 23, no. 2, pp. 199-227, 2000.

[18] T. Mainhard, R. van der Rijst, J. van Tartwijk, and T. Wubbels, "A model for the supervisor-doctoral student relationship," Higher Education, vol. 58, no. 3, pp. 359-373, 2009.

[19] C. Golde and G. Walker, Envisioning the Future of Doctoral Education: Preparing Stewards of the Discipline, Jossey-Bass, San Francisco, Calif, USA, 2006.

[20] Federal Ministry of Information, "FG sets benchmark for postgraduate programmes in Nigerian varsities," March 2012, http:// fmi.gov.ng/fg-sets-benchmark-for-post-graduate-programmes-in-nigerian-varsities/.
[21] P. Okebukola, The State of University Education in Nigeria, National University Commission, Abuja, Nigeria, 2002.

[22] A. Olukoju, "The crisis of research and academic publishing in Nigerian universities: the twentieth century and beyond," in Proceedings of the 28th Annual Spring Symposium on African Universities in the 21st Century, pp. 1-17, University of Illinois/CODESRIA, Dakar, Senegal, April 2002.

[23] C. Manathunga, "Supervisors watching supervisors. The deconstructive possibilities and tensions of team supervision," Australian Universities Review, vol. 54, no. 1, pp. 29-37, 2012.

[24] L. O. K. Lategan, "Why the fuss about research and postgraduate supervision?" in An Introduction to Postgraduate Supervision, L. O. K. Lategan, Ed., African Sun Media, Stellenbosch, South Africa, 2008.

[25] T. Wang and L. Y. Li, ““Tell me what to do” vs. "guide me through it": feedback experiences of international doctoral students," Active Learning in Higher Education, vol. 12, no. 2, pp. 101-112, 2011.

[26] T. Vilkinas, "An exploratory study of the supervision of Ph.D./research students' theses," Innovative Higher Education, vol. 32, no. 5, pp. 297-311, 2008.

[27] G. M. Gurr, "Negotiating the "Rackety Bridge"-a dynamic model for aligning supervisory style with research student development," Higher Education Research \& Development, vol. 20, no. 1, pp. 81-92, 2001.

[28] A. Blumberg, Supervisor and Teaching. A Private Cold War, McCutchan, Berkely, Calif, USA, 1974.

[29] J. Anderson, The Supervisory Process in Speech Language Pathology and Audiology, College Hill Press and Little Brown, Boston, Mass, USA, 1988.

[30] O. Dysthe, "Professors as mediators of academic text cultures: An interview study with advisors and master's degree students in three disciplines in a Norwegian University," Written Communication, vol. 19, no. 4, pp. 493-544, 2002.

[31] S. Knowles, "Feedback on writing in postgraduate supervision: echoes in response-context, continuity and resonance," in Supervision of Postgraduate Research Education, A. Holbrook and S. Johnson, Eds., pp. 113-128, Australian Association for Research in Education, Coldstream, Australia, 1999.

[32] V. Kumar and E. Stracke, "An Analysis of written feedback on a PhD thesis," Teaching in Higher Education, vol. 12, no. 4, pp. 461-470, 2007.

[33] P. Race, Making Learning Happen. A Guide for Post-Compulsory Education, SAGE, London, UK, 2005.

[34] M. de Beer and R. B. Mason, "Using a blended approach to facilitate postgraduate supervision," Innovations in Education and Teaching International, vol. 46, no. 2, pp. 213-226, 2009.

[35] Federal Republic of Nigeria, Social Statistics in Nigeria, National Bureau of Statistics, Abuja, Nigeria, 2009.

[36] K. M. Elliot and D. Shin, "Student satisfaction: an alternative approach to assessing this important concept," Journal of Higher Education Policy and Management, vol. 24, no. 2, pp. 197-209, 2002.

[37] T. Gruber, S. Fuß, R. Voss, and M. Gläser-Zikuda, "Examining student satisfaction with higher education services: using a new measurement tool," International Journal of Public Sector Management, vol. 23, no. 2, pp. 105-123, 2010.

[38] H. E. Campbell, K. Gerdes, and S. Steiner, "What's looks got to do with it? Instructor appearance and student evaluations of teaching," Journal of Policy Analysis and Management, vol. 24, no. 3, pp. 611-620, 2005. 
[39] N. Vevere and V. Kozlinskis, "Students' evaluation of teaching quality," US-China Education Review B, vol. 5, pp. 702-708, 2011.

[40] C. Glymour, "Why the university should abolish faculty course evaluations," 2003, http/www.hss.cmu.edu/philosophy/facultyglymour.php.

[41] D. Hammermesh and A. Parker, "Beauty in the classroom: professor's pulchritude and putative pedagogical productivity," NBER Working Papers 9853, National Bureau of Economic Research, Cambridge, Mass, USA, 2003.

[42] M. W. Lindahl and M. L. Unger, "Cruelty in student teaching evaluations," College Teaching, vol. 58, pp. 71-76, 2010.

[43] F. Zabaleta, "The use and misuse of student evaluations of teaching," Teaching in Higher Education, vol. 12, no. 1, pp. 5576, 2007.

[44] H. W. Marsh, K. J. Rowe, and A. Martin, "PhD students' evaluations of research supervision: issues, complexities, and challenges in a nationwide Australian experiment in benchmarking universities," The Journal of Higher Education, vol. 73, no. 3, pp. 313-348, 2002. 

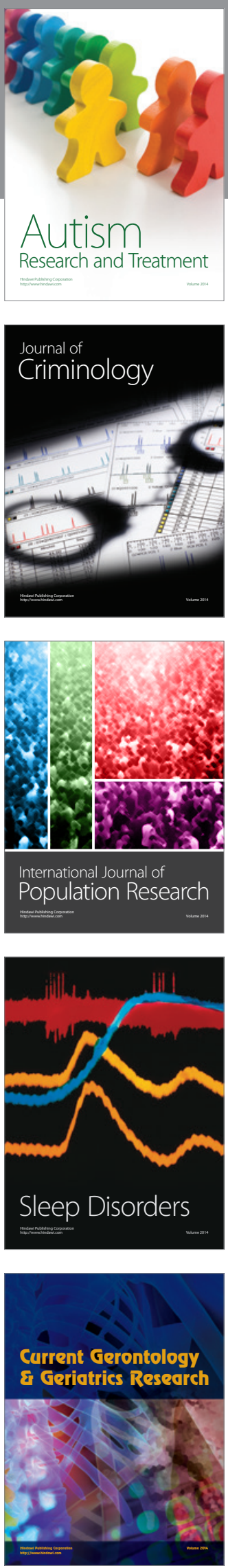
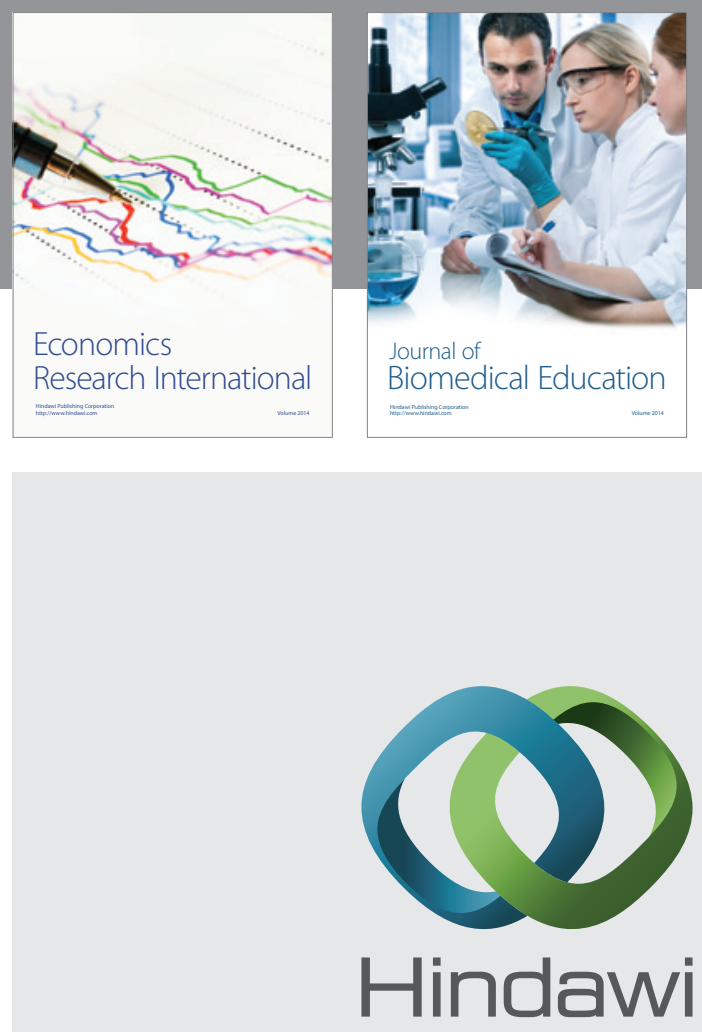

Submit your manuscripts at

http://www.hindawi.com
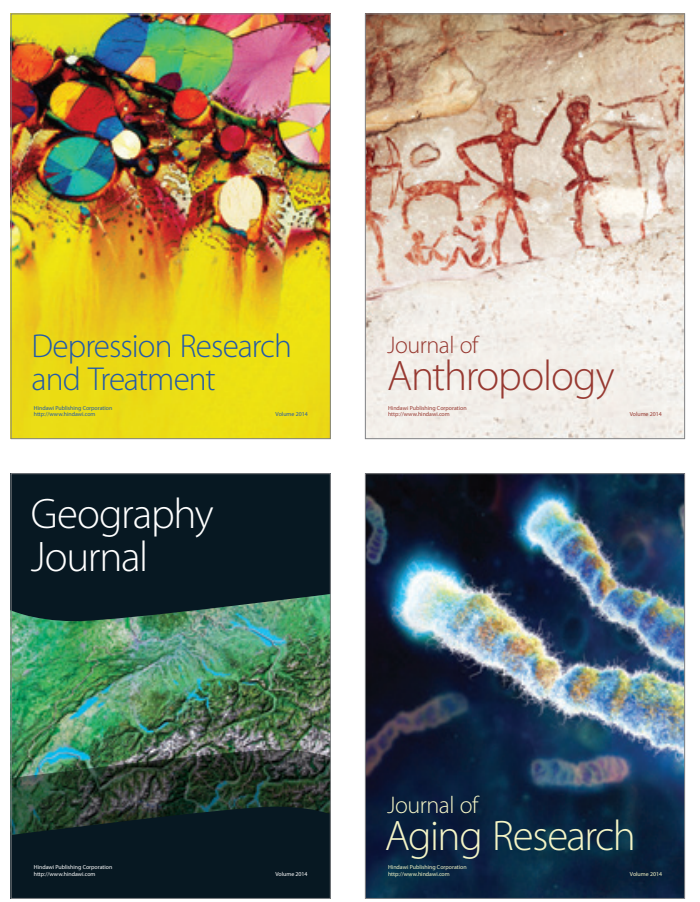
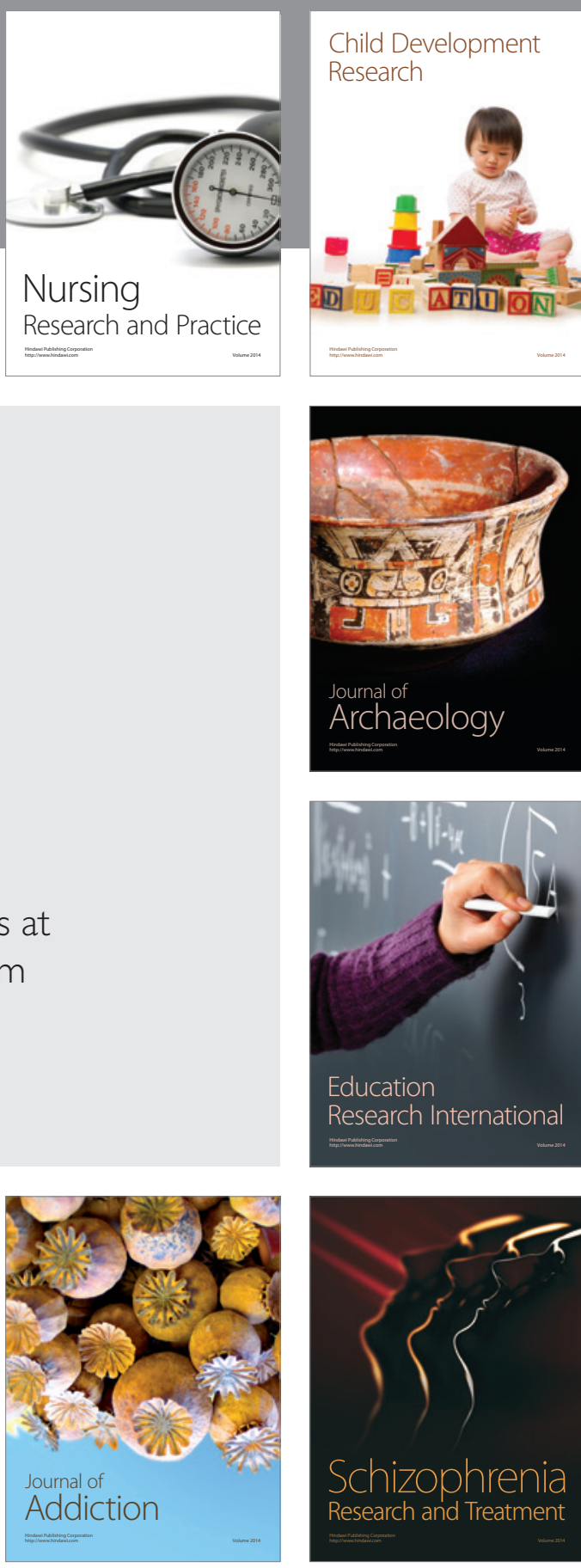

(D)
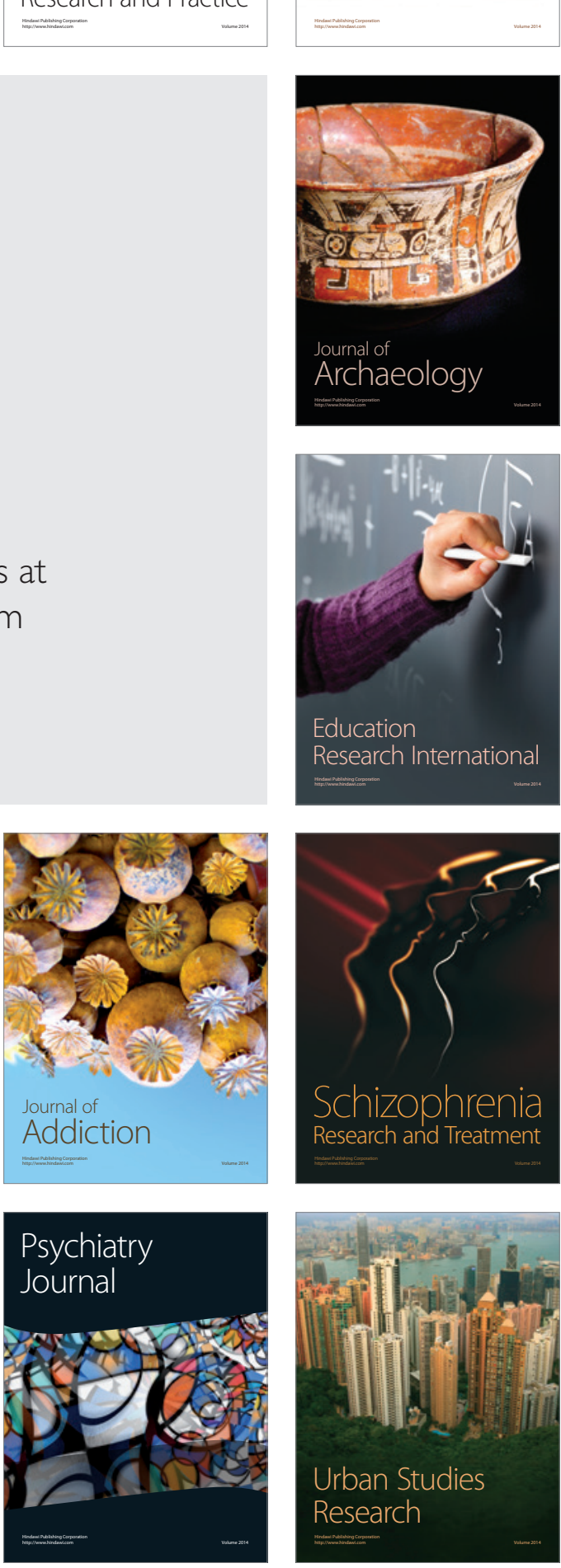